\title{
Dietary Diversity and Nutritional Status of Urban Primary School Children from Iran and India
}

\section{Sahar Hooshmand ${ }^{1 *}$ and Shobha A Udipi ${ }^{2}$}

${ }^{1}$ Department of Food Science and Nutrition, S.N.D.T. Women's University, Juhu, Mumbai-400049, India

${ }^{2}$ Professor, Department of Food Science and Nutrition, S.N.D.T. Women's University, Juhu, Mumbai-400049, India

\begin{abstract}
Introduction: Nutritional status of children is influenced by diet. Better dietary diversity helps ensure adequate intake of essential nutrients especially for growing school going children. The aim of this study was to assess the effect of dietary scores and nutritional status of urban Iranian and Indian school children.

Methods: The present study examined dietary diversity, weight-for-age (WA) and height-for-age (HA) and weightfor-height weight-for-age z-scores and nutritional status of 4570 children aged 6-9 years, including 2234 Iranian (1016 boys, 1218 girls) and 2336 Indian (1240 boys, 1096 girls) attending primary schools residing in Mumbai and Ahwaz, Iran, from low and middle income categories. Dietary diversity scores were assessed based on frequency of consumption of individual food items categorized into 11 individual food groups.

Results: Total dietary diversity scores were significantly higher for Indian children who had normal weight or who were overweight $(F=32.197, p=0.000)$ and lowest for underweight children. Similar trends were observed for the children from Iran $(F=9.345, p=0.000)$. Total food group scores increased with better height status of the children. In both countries, severely and moderately stunted children had lower total mean scores than those who had normal and above average height. Wasting was also associated with lower total mean scores. Analysis of data for individual food groups showed that increasing weight was associated with higher scores for almost all food groups in India. In Iran, mean scores for vegetables, beverages, sweets and fats increased with increasing weight. Heights for age z-scores were positively associated with a mean score for pulses in countries and dairy products, beverages and fats. Higher BMI was associated with higher scores for cereals, fruits, vegetables, dairy products, mixed dishes, beverages, sweets and fats.
\end{abstract}

Keywords: Dietary diversity; Nutritional status; Essential nutrients; Anthropometric measurements

Abbreviations: BF: Breast Feeding; DDS: Dietary Diversity Score; DS: Dietary Score; FVS: Food Variety Score; HAZ: Height-for-Age Z-scores; SES: Socio Economic Status

\section{Introduction}

All people need a variety of foods to meet requirements for essential nutrients, and the value of a diverse diet has long been recognized. Lack of diversity is a particularly severe problem among poor populations in the developing world [1]. For vulnerable growing children, the problem is particularly critical because they need energy- and nutrient-dense foods to grow and develop both physically and mentally and to live a healthy life.Because of the perceived importance of dietary diversity for health and nutrition; indicators of dietary diversity have become increasingly popular in recent years [2]. These types of indicators are particularly attractive because they are relatively simple to measure and they are thought to reflect nutrient adequacy, i.e., individuals consuming more diverse diets are thought to be more likely to meet their nutrient needs [3].

Dietary variety instruments (often called dietary diversity scores or food variety scores) have recently become the preferred method for studying dietary adequacy in developing countries. These scores consider the number of different food items or food groups contributing to the diet in a given time period. They are useful because they are correlated with nutrient intakes as well as various anthropometric measures in children; measurements are simple to collect and easily adapted to diet in various settings. They have been used to study diet in both early childhood and adulthood [4].

Nutritional status of children is influenced by diet. Shetty has stated that both under nutrition and over nutrition could be reduced by increasing the diversity of foods available for consumption [5]. Studies in different countries have shown that in general, children's eating patterns have changed over the years with the trends being eating more food away from home, consuming more snacks, drinking more sugar sweetened beverages, [6] along with a decline in breakfast consumption [7] and less consumption of fruits. Ruel and Seo have stated that dietary diversity is associated with child nutritional status and growth $[8,9]$.

This study was undertaken to determine the association between dietary diversity and underweight, stunted and wasted school children 6-9 years of age in urban Iran and India. Dietary diversity was examined by calculating scores for 11 food groups. The scores were calculated taking into consideration the number of times different items that were consumed.

\section{Methodology}

A well-nourished child is one with access to adequate food supply, care and health. Such a child will have weight and height measurements that compare very well with the standard normal distribution of heights $(\mathrm{H})$ and weights $(\mathrm{W})$ of healthy children of the same age and sex. Thus, the best way to evaluate the nutritional status and overall health of a child is to compare the child's growth indices with the set cut-off points

*Corresponding author: Sahar Hooshmand, Department of Food Science and Nutrition, S.N.D.T. Women's University, Juhu, Mumbai-400049, India, E-mail: Hooshmand_sahar@yahoo.com

Received February 12, 2013; Accepted February 27, 2013; Published March 01, 2013

Citation: Hooshmand S, Udipi SA (2013) Dietary Diversity and Nutritional Status of Urban Primary School Children from Iran and India. J Nutr Disorders Ther S12 001. doi:10.4172/2161-0509.S12-001

Copyright: @ 2013 Hooshmand S, et al. This is an open-access article distributed under the terms of the Creative Commons Attribution License, which permits unrestricted use, distribution, and reproduction in any medium, provided the original author and source are credited. 
in the standard normal distribution of well nourished children that are associated with adequate growth [10].

This study was carried out in Mumbai city located in Maharashtra state of western India in Konkan division and in Ahwaz city which is situated in Khoozesan state in the south west of Iran. Mumbai possesses a mix of different socio economic groups. Data for this study were obtained from a cross-sectional survey designed to evaluate the nutritional status and dietary diversity 4570 school going children (aged 6-9 years) in Mumbai, and Ahwaz, Iran. From these, 2234 Iranian school children (1218 girls and 1016 boys) and 2336 Indian school children (1096 girls and 1240 boys) were included in the present study. The study also received approval from the Ethics Committee of department of post graduate studies and research in home science S.N.D.T. Women's university, Mumbai, India.

Anthropometric measurements:In practice, growth references are used by physicians and nurses involved in the care of individual children as a part of medical assessment to evaluate the growth status of a child, and as a public health tool, to summarize and compare anthropometry among groups of children [11]. Height and weight were determined according to standard anthropometric methods [12]. Height was measured to the nearest 0.1 centimeters $(\mathrm{cm})$ in bare feet with participants standing upright against a mounted stadiometer. Weight was measured to the nearest 0.1 kilograms $(\mathrm{kg})$ with participants lightly dressed using a portable Seca digital platform scale (model 770). Body Mass Index was computed as weight $/$ height $^{2}\left(\mathrm{~kg} \mathrm{~m}^{-2}\right)$.

Nutritional status: The World Health Organization's (WHO) Anthro Plus software which is software for the global application of the WHO reference 2007 for 5-19 years to monitor the growth of school age children and adolescents was used to assess the nutritional status of the children. Three indicators were measured by this software: weight for age, height for age and Body Mass Index for age. The indicators were calculated by standard deviation (SD) or Z-score for all children. Weight for age, height for age and weight for height less than -3SD shows severe underweight, severe stunting and severe wasting. Weight for age, height for age and weight for height between -3SD to -2SD is classified as moderately underweight, moderately stunted and moderately wasted. Children with weight or height or weight for height between -2SD to $+2 \mathrm{SD}$ were classified as normal weight, normal height and normal Body Mass Index. Weigh for age, height for age and weight for height more than $+2 \mathrm{SD}$ were indicative of overweight, tall stature and obesity, respectively.

Dietary diversity: In the present study, the frequency of consumption for the different food items was recorded i.e. daily, 2-3 times per week, once per week, fortnightly, monthly and occasionally. The main food groups for both Iranian and Indian population were similar but the items within groups were different among Iranian and Indian population as their food recipes are different, hence the food frequency questionnaire was designed separately for the two groups. In addition, a food frequency questionnaire was used. The record period should represent usual diet at community level and should reduce memory bias and avoid respondent fatigue. The most common recording periods is 1 day to 1 week. The most common scoring system to determine dietary diversity is scoring with weighting and the other one usually simple count without weighting. In the present study, the second system was used and the scores were calculated as follows in table 1:

Dietary diversity score was calculated by summing the number of food or food items for each food group separately. In addition, the total scores were calculated.

\begin{tabular}{|c|c|}
\hline Number of times consumed & Score assigned \\
\hline Daily & 7 \\
\hline 2-3times/week & 3 \\
\hline Once/week & 1 \\
\hline Fortnight & 0.5 \\
\hline Monthly & 0.25 \\
\hline Occasionally & 0 \\
\hline
\end{tabular}

Table 1: Scores calculation based on food intake frequencies.

\section{Results and Discussions}

In the present study dietary diversity scores were examined in relation to the nutritional status of the children (Table 2). Total dietary diversity scores were significantly higher for Indian children who had normal weight or who had over weight $(\mathrm{F}=32.197, \mathrm{p}=0.000)$, similar trends were observed for the children from Iran $(\mathrm{F}=9.345, \mathrm{p}=0.000)$. Total food group mean scores were observed to be the lowest for severely underweight children and did not differ significantly from the mean scores for those who were moderately underweight in both countries. Scores were highest among overweight children in both countries. Total food group scores increased with better height status of the children (India - F=10.759, p=0.000 and Iran- F=5.825, $\mathrm{p}=0.001)$. In both countries severely and moderately stunted children had lower total food mean scores than those who had normal and above the average height. Total food mean scores were also observed to be lower among moderately wasted children than children who were normal or obese in India $(\mathrm{F}=40.831, \mathrm{p}=0.000)$ as well as in Iran $(\mathrm{F}=16.038, \mathrm{p}=0.000)$. These data suggest that less dietary diversity may be associated with child under nutrition. On the other hand, greater diversity is associated with overweight and obesity. Hence, individual food group diversity scores were analyzed in order to determine which food groups may put the child at risk of overweight and/or obesity. Tables $3 a-3 c$ present the scores for individual food groups in relation to weight for age $\mathrm{z}$-scores, height for age $\mathrm{z}$-scores and weight for height z-scores, respectively.

Mean score for cereal consumption increased with increasing child's weight in India, with the score being approximately twice the scores for children who were severely underweight. In Iran the highest mean score for cereals observed in overweight children and lower scores were observed among moderately underweight children. The mean scores for pulses, vegetables, fruits, nuts, beverages and fat consumption increased with increasing weight in India, whereas in Iran there was no significant difference in mean scores among different weight for age categories.

Mean scores for vegetables, beverages, sweets and fats consumption in Iran increased with increasing weight. In Iran the highest score for fruit observed among overweight children and the lowest score observed among moderately underweight children.

In India the lowest score for dairy products belonged to moderately under weight and the higher score was observed in overweight children. Mean score for non-vegetarian. Foods consumption in India was high among moderately underweight as well as overweight children whereas in Iran it increased with increasing weight. In Iran mean score for nuts consumption was lower in moderately underweight children, whereas the score was high among sever underweight children. In India the score for mixed dishes consumption observed more in overweight children and less in moderate underweight children. The means score for sweet consumption in India was higher among overweight children.

In both countries mean scores for cereals, vegetables, fruits, nuts, mixed dishes and sweet consumption increased by increasing child's 
Citation: Hooshmand S, Udipi SA (2013) Dietary Diversity and Nutritional Status of Urban Primary School Children from Iran and India. J Nutr Disorders Ther S12: 001. doi:10.4172/2161-0509.S12-001

Page 3 of 5

\begin{tabular}{|c|c|c|c|c|}
\hline \multirow[b]{2}{*}{ z-scores } & \multirow[b]{2}{*}{ Location } & \multicolumn{3}{|c|}{ Total food group scores } \\
\hline & & $\begin{array}{l}\text { Weight/Age } \\
\text { Mean } \pm \text { SD }\end{array}$ & $\begin{array}{l}\text { Height/Age } \\
\text { Mean } \pm \text { SD }\end{array}$ & $\begin{array}{c}\text { Weight/Height } \\
\text { Mean } \pm \text { SD }\end{array}$ \\
\hline \multirow{2}{*}{$<-3 S D$} & India & $120.5 \pm 19.0$ & $0.0 \pm 0.0$ & $127.0 \pm 26.2$ \\
\hline & Iran & $123.8 \pm 40.0$ & $113.0 \pm 16.4$ & $0.0 \pm 0.0$ \\
\hline \multirow{2}{*}{$-3 S D$ to $-2 S D$} & India & $119.4 \pm 31.5$ & $131 \pm 38.3$ & $116.2 \pm 24.5$ \\
\hline & Iran & $129.4 \pm 53.5$ & $133.0 \pm 53.7$ & $125.2 \pm 39.5$ \\
\hline \multirow{2}{*}{$-2 S D$ to $+2 S D$} & India & $146.8 \pm 40.6$ & $146.5 \pm 41.1$ & $147.0 \pm 40.6$ \\
\hline & Iran & $149.6 \pm 51.8$ & $151.2 \pm 51.9$ & $149.6 \pm 51.9$ \\
\hline \multirow{2}{*}{ >+2SD } & India & $213.4 \pm 30.9$ & $191.4 \pm 16.6$ & $207.0 \pm 37.4$ \\
\hline & Iran & $178.1 \pm 45.9$ & $156.3 \pm 43.7$ & $177.5 \pm 48.7$ \\
\hline
\end{tabular}

Table 2: Total food group scores based on nutritional status in Iran and India.

\begin{tabular}{|c|c|c|c|c|c|c|c|c|}
\hline \multirow[b]{3}{*}{ Food groups } & \multicolumn{8}{|c|}{ Weight for Age } \\
\hline & \multicolumn{2}{|c|}{$<3 S D$} & \multicolumn{2}{|c|}{$-3 S D$ to $-2 S D$} & \multicolumn{2}{|c|}{$-2 S D$ to $+2 S D$} & \multicolumn{2}{|c|}{$>+2 S D$} \\
\hline & $\begin{array}{c}\text { India } \\
X \pm S D\end{array}$ & $\begin{array}{c}\text { Iran } \\
X \pm S D\end{array}$ & $\begin{array}{l}\text { India } \\
X \pm S D\end{array}$ & $\begin{array}{c}\text { Iran } \\
X \pm S D\end{array}$ & $\begin{array}{l}\text { India } \\
X \pm S D\end{array}$ & $\begin{array}{c}\text { Iran } \\
X \pm S D\end{array}$ & $\begin{array}{c}\text { India } \\
X \pm S D\end{array}$ & $\begin{array}{c}\text { Iran } \\
X \pm S D\end{array}$ \\
\hline Cereals & $19.8 \pm 0.1$ & $18.1 \pm 0.0$ & $21.9 \pm 5.8$ & $15.5 \pm 6.1$ & $25.7 \pm 7.1$ & $17.4 \pm 7.8$ & $36.3 \pm 5.2$ & $19.5 \pm 6.4$ \\
\hline Pulse and legumes & $12.7 \pm 0.0$ & $4.4 \pm 2.3$ & $13.5 \pm 4.4$ & $4.9 \pm 6.7$ & $14.0 \pm 4.4$ & $4.1 \pm 4.2$ & $17.8 \pm 4.9$ & $4.7 \pm 3.2$ \\
\hline Vegetables & $24.7 \pm 4.9$ & $19.1 \pm 0.9$ & $25.9 \pm 12.2$ & $22.1 \pm 11.1$ & $30.6 \pm 10.8$ & $24.3 \pm 15.7$ & $39.7 \pm 10.0$ & $31.3 \pm 12.7$ \\
\hline Fruits & $6.9 \pm 2.3$ & $17.1 \pm 11.5$ & $7.5 \pm 7.9$ & $16.1 \pm 13.1$ & $10.4 \pm 6.0$ & $20.4 \pm 14.4$ & $19.1 \pm 10.4$ & $23.6 \pm 13.5$ \\
\hline Dairy products & $10.3 \pm 1.1$ & $18.5 \pm 2.7$ & $9.5 \pm 2.9$ & $17.7 \pm 13.5$ & $12.3 \pm 5.7$ & $16.4 \pm 8.6$ & $19.4 \pm 6.4$ & $17.0 \pm 5.5$ \\
\hline Non veg items & $0.0 \pm 0$ & $7.7 \pm 3.4$ & $0.8 \pm 2.2$ & $8.2 \pm 5.3$ & $0.4 \pm 1.1$ & $8.8 \pm 4.4$ & $0.8 \pm 2.3$ & $12.0 \pm 4.6$ \\
\hline Nuts & $0.2 \pm 0.3$ & $6.6 \pm 7.7$ & $0.9 \pm 1.6$ & $2.9 \pm 5.3$ & $1.6 \pm 1.8$ & $4.3 \pm 5.2$ & $3.5 \pm 2.0$ & $4.3 \pm 4.0$ \\
\hline Mixed dishes & $14.2 \pm 5.0$ & $14.2 \pm 9.3$ & $9.2 \pm 5.0$ & $9.0 \pm 5.8$ & $14.2 \pm 6.9$ & $12.9 \pm 7.2$ & $25.2 \pm 6.4$ & $16.9 \pm 8.1$ \\
\hline Beverages & $5.8 \pm 3.7$ & $4.0 \pm 2.7$ & $6.4 \pm 2.8$ & $10.6 \pm 6.3$ & $9.3 \pm 3.4$ & $11.3 \pm 6.3$ & $13.4 \pm 3.4$ & $14.7 \pm 4.0$ \\
\hline Sweets & $16.3 \pm 0.7$ & $8.1 \pm 0.8$ & $14.3 \pm 6.0$ & $15.6 \pm 10.4$ & $17.8 \pm 6.7$ & $19.5 \pm 10.9$ & $23.6 \pm 3.4$ & $22.6 \pm 8.9$ \\
\hline Fats & $9.4 \pm 1.9$ & $5.8 \pm 1.1$ & $9.2 \pm 2.0$ & $6.6 \pm 2.4$ & $10.5 \pm 3.0$ & $10.0 \pm 4.2$ & $14.4 \pm 3.1$ & $11.4 \pm 3.5$ \\
\hline
\end{tabular}

Table 3a: Mean Diversity Scores for Individual Groups in relation to Weight for Age z Scores.

\begin{tabular}{|c|c|c|c|c|c|c|c|c|}
\hline \multirow[b]{3}{*}{ Food groups } & \multicolumn{8}{|c|}{ Height for Age } \\
\hline & \multicolumn{2}{|c|}{$<3 S D$} & \multicolumn{2}{|c|}{$-3 S D$ to $-2 S D$} & \multicolumn{2}{|c|}{$-2 S D$ to $+2 S D$} & \multicolumn{2}{|c|}{$>+2 S D$} \\
\hline & $\begin{array}{c}\text { India } \\
X \pm S D\end{array}$ & $\begin{array}{l}\text { Iran } \\
X \pm S D\end{array}$ & $\begin{array}{c}\text { India } \\
X \pm S D\end{array}$ & $\underset{X \pm S D}{\text { Iran }}$ & $\begin{array}{l}\text { India } \\
X \pm S D\end{array}$ & $\underset{X \pm S D}{\text { Iran }}$ & $\begin{array}{c}\text { India } \\
X \pm S D\end{array}$ & $\begin{array}{c}\text { Iran } \\
X \pm S D\end{array}$ \\
\hline Cereals & $0.0 \pm 0$ & $14.2 \pm 2.6$ & $23.1 \pm 6.0$ & $16.9 \pm 9.8$ & $25.7 \pm 7.2$ & $17.5 \pm 7.7$ & $28.9 \pm 6.6$ & $18.0 \pm 5.4$ \\
\hline Pulse \&legumes & $0.0 \pm 0$ & $4.1 \pm 2.2$ & $12.8 \pm 5.0$ & $3.9 \pm 6.1$ & $14.0 \pm 4.4$ & $4.1 \pm 4.1$ & $15.1 \pm 1.9$ & $4.9 \pm 3.2$ \\
\hline Vegetables & $0.0 \pm 0$ & $17.5 \pm 8.4$ & $30.6 \pm 15.4$ & $21.1 \pm 14$ & $30.5 \pm 10.8$ & $24.7 \pm 15.7$ & $38.4 \pm 9.1$ & $27.6 \pm 13.4$ \\
\hline Fruits & $0.0 \pm 0$ & $10.1 \pm 5.0$ & $8.9 \pm 7.6$ & $17.4 \pm 14.8$ & $10.4 \pm 6.1$ & $20.6 \pm 14.4$ & $15.7 \pm 3.3$ & $20.8 \pm 10.1$ \\
\hline Dairy products & $0.0 \pm 0$ & $15.2 \pm 4.8$ & $11.5 \pm 4.0$ & $13.9 \pm 7.0$ & $12.2 \pm 5.7$ & $16.7 \pm 8.7$ & $18.1 \pm 4.6$ & $14.5 \pm 6.7$ \\
\hline Non veg items & $0.0 \pm 0$ & $5.8 \pm 4.0$ & $0.0 \pm 0$ & $8.3 \pm 3.4$ & $0.4 \pm 1.2$ & $9.0 \pm 4.5$ & $0.82 \pm 1.6$ & $10.1 \pm 4.7$ \\
\hline Nuts & $0.0 \pm 0$ & $1.1 \pm 0.5$ & $1.3 \pm 1.0$ & $2.8 \pm 4.4$ & $1.5 \pm 1.8$ & $4.4 \pm 5.2$ & $3.2 \pm 1.0$ & $3.9 \pm 3.7$ \\
\hline Mixed dishes & $0.0 \pm 0$ & $9.3 \pm 3.0$ & $12.2 \pm 7.0$ & $10.4 \pm 6.7$ & $14.1 \pm 7.0$ & $13.1 \pm 7.3$ & $19.4 \pm 6.7$ & $14.3 \pm 6.5$ \\
\hline Beverages & $0.0 \pm 0$ & $11.0 \pm 3.0$ & $7.0 \pm 2.4$ & $10.6 \pm 6.0$ & $9.2 \pm 3.5$ & $11.5 \pm 6.3$ & $14.7 \pm 2.3$ & $11.6 \pm 4.4$ \\
\hline Sweets & $0.0 \pm 0$ & $15.1 \pm 1.9$ & $14.9 \pm 5.7$ & $18.6 \pm 10.7$ & $17.8 \pm 6.7$ & $19.7 \pm 10.9$ & $24.4 \pm 5.5$ & $21.1 \pm 8.5$ \\
\hline Fats & $0.0 \pm 0$ & $9.4 \pm 2.1$ & $9.6 \pm 1.2$ & $9.0 \pm 3.7$ & $10.3 \pm 3.0$ & $10.0 \pm 4.3$ & $12.4 \pm 2.1$ & $9.5 \pm 3.9$ \\
\hline
\end{tabular}

Table 3b: Mean Diversity Scores for Individual Groups in relation to Height for Age z Scores.

\begin{tabular}{|c|c|c|c|c|c|c|c|c|}
\hline \multirow[b]{3}{*}{ Food groups } & \multicolumn{8}{|c|}{ Weight for Height } \\
\hline & \multicolumn{2}{|c|}{$<3 S D$} & \multicolumn{2}{|c|}{$-3 S D$ to $-2 S D$} & \multicolumn{2}{|c|}{$-2 S D$ to $+2 S D$} & \multicolumn{2}{|c|}{$>+2 S D$} \\
\hline & $\begin{array}{c}\text { India } \\
X \pm S D\end{array}$ & $\begin{array}{c}\text { Iran } \\
X \pm S D\end{array}$ & $\begin{array}{l}\text { India } \\
X \pm S D\end{array}$ & $\begin{array}{c}\text { Iran } \\
X \pm S D\end{array}$ & $\begin{array}{l}\text { India } \\
X \pm S D\end{array}$ & $\begin{array}{c}\text { Iran } \\
X \pm S D\end{array}$ & $\begin{array}{c}\text { India } \\
X \pm S D\end{array}$ & $\begin{array}{c}\text { Iran } \\
X \pm S D\end{array}$ \\
\hline Cereals & $22.3 \pm 5.8$ & $0.0 \pm 0$ & $22.2 \pm 5.6$ & $13.8 \pm 4.0$ & $25.7 \pm 7.1$ & $17.4 \pm 7.8$ & $33.9 \pm 6.4$ & $20.0 \pm 6.8$ \\
\hline Pulse \&legumes & $15.4 \pm 5.1$ & $0.0 \pm 0$ & $12.3 \pm 3.1$ & $4.2 \pm 3.3$ & $14.0 \pm 4.4$ & $4.1 \pm 4.2$ & $17.2 \pm 5.8$ & $4.4 \pm 3.6$ \\
\hline Vegetables & $22.9 \pm 6.6$ & $0.0 \pm 0$ & $23.4 \pm 8.4$ & $18.4 \pm 9.1$ & $30.7 \pm 10.8$ & $24.3 \pm 15.6$ & $40.4 \pm 8.6$ & $33.3 \pm 14.1$ \\
\hline Fruits & $8.9 \pm 6.1$ & $0.0 \pm 0$ & $6.7 \pm 5.0$ & $14.3 \pm 8.5$ & $10.4 \pm 6.1$ & $20.4 \pm 14.4$ & $17.8 \pm 6.1$ & $23.9 \pm 13.1$ \\
\hline Dairy products & $10.0 \pm 3.3$ & $0.0 \pm 0$ & $10.1 \pm 3.2$ & $15.1 \pm 10.2$ & $12.3 \pm 5.7$ & $16.5 \pm 8.7$ & $19.0 \pm 7.4$ & $16.7 \pm 5.6$ \\
\hline Non veg items & $0.4 \pm 1.2$ & $0.0 \pm 0$ & $0.8 \pm 2.1$ & $7.4 \pm 3.1$ & $0.4 \pm 1.1$ & $8.9 \pm 4.4$ & $1.0 \pm 2.2$ & $11.5 \pm 4.6$ \\
\hline Nuts & $1.8 \pm 2.2$ & $0.0 \pm 0$ & $0.6 \pm 0.8$ & $3.4 \pm 3.6$ & $1.6 \pm 1.8$ & $4.3 \pm 5.2$ & $3.2 \pm 2.0$ & $4.1 \pm 4.0$ \\
\hline Mixed dishes & $10.2 \pm 2.0$ & $0.0 \pm 0$ & $9.9 \pm 5.0$ & $11.9 \pm 6.5$ & $14.2 \pm 7.0$ & $12.8 \pm 7.2$ & $23.6 \pm 7.0$ & $17.3 \pm 8.3$ \\
\hline Beverages & $8.9 \pm 3.6$ & $0.0 \pm 0$ & $6.7 \pm 3.0$ & $9.8 \pm 6.7$ & $9.3 \pm 3.4$ & $11.4 \pm 6.3$ & $13.2 \pm 3.5$ & $13.5 \pm 4.8$ \\
\hline Sweets & $15.9 \pm 6.3$ & $0.0 \pm 0$ & $14.3 \pm 5.4$ & $18.6 \pm 12.4$ & $17.8 \pm 6.7$ & $19.5 \pm 10.8$ & $23.7 \pm 6.9$ & $20.6 \pm 10.3$ \\
\hline Fats & $10.1 \pm 2.4$ & $0.0 \pm 0$ & $9.1 \pm 1.8$ & $8.1 \pm 3.1$ & $10.5 \pm 2.9$ & $9.9 \pm 4.2$ & $13.9 \pm 3.7$ & $12.1 \pm 5.5$ \\
\hline
\end{tabular}

Table 3c: Mean Diversity Scores for Individual Groups in relation to Weight for Height $z$ Scores. 
Citation: Hooshmand S, Udipi SA (2013) Dietary Diversity and Nutritional Status of Urban Primary School Children from Iran and India. J Nutr Disorders Ther S12: 001. doi:10.4172/2161-0509.S12-001

Page 4 of 5

\begin{tabular}{|c|c|c|c|c|}
\hline Author & Country & Age group & $\begin{array}{l}\text { Dietary diversity } \\
\text { approach (indicator) }\end{array}$ & Main findings \\
\hline Onyango et al. [16] & Kenya & 12-36 mo. & No. of foods & $\begin{array}{l}\text { 1) Diversity associated with HAZ, WAZ, WHZ, } \\
\text { TS and MUAC; } \\
\text { 2) Diversity }>5 \text { more important for HAZ among } \\
\text { non-BF children (difference between diversity } \\
\text { groups: } 0.9 \mathrm{HAZ} \text { among non-BF, vs. } 0.2 \text { among } \\
\text { BF }\end{array}$ \\
\hline $\begin{array}{l}\text { Arimond and } \\
\text { Ruel [3] }\end{array}$ & $\begin{array}{l}\text { Ethiopia DHS } \\
\text { data }\end{array}$ & $12-36 \mathrm{mo}$ & $\begin{array}{l}\text { 1) } 24-h \text { food group } \\
\text { diversity: } 8 \text { groups: } \\
\text { grains, roots/tubers, milk, } \\
\text { vitamin A-rich } \\
\text { fruits/vegetables, other } \\
\text { fruits/vegetables, } \\
\text { meat/poultry/fish/cheese/ } \\
\text { eggs/yogurt, legumes, } \\
\text { fats/oils } \\
\text { 2) 7-day food group } \\
\text { diversity: (same as above } \\
\text { except grains combined } \\
\text { with roots/tubers }(n=7)\end{array}$ & $\begin{array}{l}\text { 1) Both 24-hour and 7-day food group diversity } \\
\text { strongly associated with HAZ, controlling for } \\
\text { child, maternal and household socioeconomic } \\
\text { factors. } \\
\text { 2) Differences in adjusted mean HAZ between } \\
\text { lowest and highest tercile of } 24 \text {-hour diversity: } \\
0.65 \text { Z-scores } \\
\text { 7-day diversity: } 0.67 \text { Z-scores }\end{array}$ \\
\hline Allen et al. [18] & Mexico & $18-30 \mathrm{mo}$. & $\begin{array}{l}8 \text { food groups: } \\
5 \text { plant groups : } \\
\text { tortillas, legumes, } \\
\text { vegetables, fruits, other } \\
3 \text { animal groups: dairy, } \\
\text { eggs, meat }\end{array}$ & $\begin{array}{l}\text { 1) Positive correlation between \% energy from } \\
\text { animal foods and } H A Z \text {. Also correlation between } \\
\% \text { energy from dairy and } H A Z \text {. } \\
\text { 2) Negative correlation between \% energy from } \\
\text { plant foods (tortillas in particular) and HAZ }\end{array}$ \\
\hline $\begin{array}{l}\text { Taren and } \\
\text { Chen [19] }\end{array}$ & China & $12-47 \mathrm{mo}$. & $\begin{array}{l}\text { Food group scale }(0-7) \text { : } \\
\text { rice, egg, vegetables, } \\
\text { fruits, soybeans, meat, } \\
\text { other }\end{array}$ & $\begin{array}{l}\text { Significant difference of } 0.20 \mathrm{HAZ} \text { between } \\
\text { children who consumed }<3 \text { groups and rest of } \\
\text { sample }\end{array}$ \\
\hline Marquis et al. [20] & Peru & 12-15 mo. & $\begin{array}{l}\text { 1) } 27 \text { foods and beverages } \\
\text { consumed more than } \\
\text { twice/wk. } \\
\text { 2) } 5 \text { animal food groups: } \\
\text { cow milk, meat, organ } \\
\text { meats, eggs, fish }\end{array}$ & $\begin{array}{l}\text { 1) Association between no. animal foods and } \\
\text { length not significant as main effect. } \\
\text { 2) Interactions: a).animal foods associated with } \\
\text { length in children with low overall diversity; b) BF } \\
\text { associated with length in children with low intakes } \\
\text { of animal foods. }\end{array}$ \\
\hline Tarini et al. [21] & Niger & 24-48 mo. & $\begin{array}{l}\text { Diversity score (DS): } 11 \\
\text { food groups over } 3 \text { days } \\
\text { (see above for details) }\end{array}$ & $\begin{array}{l}\text { Association DS and growth not significant (low } \\
\text { correlations, significant only for WHZ in one } \\
\text { round) }\end{array}$ \\
\hline Hatløy et al. [22] & Mali & 6-59 mo. & $\begin{array}{l}\text { 1) Household level FVS } \\
\text { 2) DDS (same as above: } \\
\text { Hatløy, Torheim, and } \\
\text { Oshaug (1998) }\end{array}$ & $\begin{array}{l}\text { In urban areas: lower FVS or DDS has twice risk } \\
\text { of stunted or underweight; rural areas: no } \\
\text { association (controlling for SES) }\end{array}$ \\
\hline
\end{tabular}

Table 4: Summary of Studies That Assessed Dietary Diversity And Child Nutritional Status.

stature. In Iran mean score for pulses and legumes consumption were higher in better child's height status $(>+2 \mathrm{SD})$ and the lower score observed in severe stunted school children. Mean scores for pulses and legumes, beverages, dairy products and fat consumption increased by increasing height in India. Higher mean score for dairy products consumption in Iran observed in children with normal height for age and the lower score belonged to moderate stunted children. Mean scores for non-vegetarian foods increased by increasing height in Iran. Mean score for beverage consumption in Iran observed higher in better height status and low among moderate stunted children. In Iran the highest score for fat consumption observed for children with normal height.

Mean scores for cereals, fruits, vegetables, dairy products, mixed dishes, beverages, sweet and fats consumption increased by increasing body mass index (BODY MASS INDEX) in India as well as in Iran. Also high score for pulses and legumes consumption observed in obese children in both countries. Same trends were observed for nuts mean scores in India whereas in Iran the higher score for nut consumption observed among normal height children.

Kennedy and Powell [13] indicated that increased food variety with more fruit and vegetable consumption in most groups associated with lower energy consumption and thus a lower Body Mass Index and perhaps also reduces the risk of obesity.
McCrory et al. [14] found that dietary diversity within sweets, snakes, condiments and carbohydrate food was positively associated and dietary diversity within the vegetable food group was negatively with energy intake and body fatness. Also it is demonstrated that low Body Mass Index was associated with higher dietary diversity in females but not in males.

In line with the present findings, Azadbakht and Esmaillzadeh in 2010 in Iran among female 18-28 years, demonstrated that a direct association between energy intake and dietary diversity [15]. Increase energy intake was related to increasing intake of fruit, vegetables and whole grain. This study also showed that there were inverse association among dietary diversity score, obesity and abdominal adiposity.

A number of studies have looked at the association between some measure of dietary diversity and child nutritional status, as seen in table $4[16]$.

Our recent analysis of data from the Ethiopia 2000 DHS showed a strong and statistically significant association between food-group diversity measures based either on a 24-hour or seven-day recall and children's height-for-age Z-scores (HAZ) [17]. A study in Mali also documents a strong association between dietary diversity and nutritional status, for children aged 6-59 months [18-22]. In urban areas of Mali, lower food variety scores (FVS) or dietary diversity 
scores (DDS) were associated with twice the risk of being stunted or underweight, controlling for socioeconomic factors.9 No association between diversity and nutritional status was found in rural areas, however. In Kenya, diversity was measured as the number of individual foods consumed in 24 hours, using an average of three 24-hour recalls. This was significantly associated with five nutritional status indicators (HAZ, WAZ, WHZ, triceps skinfolds, and mid-upper arm circumference) among 12.36 month old children [16].

\section{Conclusion}

Association between consumption pattern of selected food groups and the height and weight of school aged children was examined. Overweight children tended to have higher scores for several food groups while those who were under weight, had lower scores. In both countries, height for age z-scores were positively associated with score for pulses, dairy products and non-vegetarian food items. The data suggest that dietary diversity for cereals, mixed dishes, beverages, sweets and fat consumption as well as fruits and vegetables is associated with increasing Body Mass Index. Dietary diversity differed between the two countries with the Iranian children having slightly higher total scores than Indian children. The association between dietary diversity and child nutritional status needs to be studied in depth and used for nutrition education to prevent childhood under nutrition as well as overweight and obesity. However there is a need for further study in this area to determine whether among fruit and vegetables, cereals preparations and mixed dishes; the type and method of preparation and consequently the energy density affect body weight and nutritional status.

\section{Acknowledgements}

The authors thank the children's parents and teachers for their support. Profound appreciation is extended to the Iranian and Indian schoolchildren who participated in the study and ministry of health and education of Iran and S.N.D.T Women's University, Mumbai, India.

\section{References}

1. http://ideas.repec.org/p/fpr/fcnddp/136.html

2. Martin-Prevel Y, Becquey E, Tapsoba S, Castan F, Coulibaly D, et al. (2012) The 2008 food price crisis negatively affected household food security and dietary diversity in urban Burkina Faso. J Nutr 142: 1748-1755.

3. Arimond M, Ruel MT (2004) Dietary diversity is associated with child nutritional status: evidence from 11 demographic and health surveys. J Nutr 134: 25792585 .

4. Daniels MC, Adair LS, Popkin BM, Truong YK (2009) Dietary diversity scores can be improved through the use of portion requirements: an analysis in young Filipino children. Eur J Clin Nutr 63: 199-208.
5. Shetty PS (2002) Nutrition transition in India. Public Health Nutr 5: 175-182.

6. Paeratakul S, Ferdinand DP, Champagne CM, Ryan DH, Bray GA (2003) Fastfood consumption among US adults and children: dietary and nutrient intake profile. J Am Diet Assoc 103: 1332-1338.

7. Jahns L, Siega-Riz AM, Popkin BM (2001) The increasing prevalence of snacking among US children from 1977 to 1996. J Pediatr 138: 493-498.

8. Ruel MT (2003) Operationalizing dietary diversity: a review of measurement issues and research priorities. J Nutr 133: 3911S-3926S.

9. Seo HS, Lee SK, Nam S (2011) Factors influencing fast food consumption behaviors of middle-school students in Seoul: an application of theory of planned behaviors. Nutr Res Pract 5: 169-178.

10. www.ajol.info/index.php/ajfand/article/download/19171/64420

11. Cole TJ, Flegal KM, Nicholls D, Jackson AA (2007) Body mass index cut offs to define thinness in children and adolescents: international survey. BMJ 335 194.

12. Marfell-Jones, M, Olds T, Stew A, Carter L (2006) International standards for anthropometric assessment. The International Society for the Advancement of Kinanthropometry. Australia.

13. Kennedy E, Powell R (1997) Changing eating patterns of American children: a view from 1996. J Am Coll Nutr 16: 524-529.

14. McCrory MA, Fuss PJ, McCallum JE, Yao M, Vinken AG, et al. (1999) Dietary variety within food groups: association with energy intake and body fatness in men and women. Am J Clin Nutr 69: 440-447.

15. Azadbakht L, Esmaillzadeh A (2011) Dietary diversity score is related to obesity and abdominal adiposity among Iranian female youth. Public Health Nutr 14 62-69.

16. Onyango A, Koski KG, Tucker KL (1998) Food diversity versus breastfeeding choice in determining anthropometric status in rural Kenyan toddlers. Int J Epidemiol 27: 484-489.

17. http://www.ifpri.cgiar.org/sites/default/files/publications/fcndp143.pdf

18. Allen LH, Black A, Backstrand J, Pelto G, Ely R, et al. (1991) An analytical approach for exploring the importance of dietary quality versus quantity in the growth of Mexican children. Food and Nutrition Bulletin 13: 95-104.

19. Taren D, Chen J (1993) A positive association between extended breastfeeding and nutritional status in rural Hubei Province, People's Republic of China. Am J Clin Nutr 58: 862-867.

20. Marquis GS, Habicht JP, Lanata CF, Black RE, Rasmussen KM (1997) Breast milk or animal-product foods improve linear growth of Peruvian toddlers consuming marginal diets. Am J Clin Nutr 66: 1102-1109.

21. Tarini A, Bakari S, Delisle H (1999) [The overall nutritional quality of the diet is reflected in the growth of Nigerian children]. Sante 9: 23-31.

22. Hatløy A, Hallund J, Diarra MM, Oshaug A (2000) Food variety, socioeconomic status and nutritional status in urban and rural areas in Koutiala (Mali). Public Health Nutr 3: 57-65. 